\title{
Laboratory Testing of Aerosol for Enclosure Air Sealing
}

Curtis Harrington and Mark Modera Western Cooling Efficiency Center - UC Davis Building Industry Research Alliance

May 2012

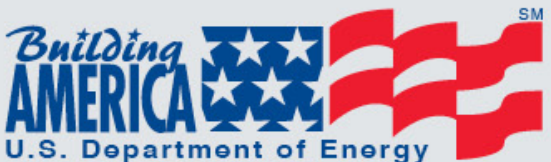




\section{This report received minimal editorial review at NREL}

\section{NOTICE}

This report was prepared as an account of work sponsored by an agency of the United States government. Neither the United States government nor any agency thereof, nor any of their employees, subcontractors, or affiliated partners makes any warranty, express or implied, or assumes any legal liability or responsibility for the accuracy, completeness, or usefulness of any information, apparatus, product, or process disclosed, or represents that its use would not infringe privately owned rights. Reference herein to any specific commercial product, process, or service by trade name, trademark, manufacturer, or otherwise does not necessarily constitute or imply its endorsement, recommendation, or favoring by the United States government or any agency thereof. The views and opinions of authors expressed herein do not necessarily state or reflect those of the United States government or any agency thereof.

Available electronically at http://www.osti.gov/bridge

Available for a processing fee to U.S. Department of Energy

and its contractors, in paper, from:

U.S. Department of Energy

Office of Scientific and Technical Information

P.O. Box 62Oak Ridge, TN 37831-0062

phone: 865.576 .8401

fax: 865.576.5728

email: mailto:reports@adonis.osti.gov

Available for sale to the public, in paper, from:

U.S. Department of Commerce

National Technical Information Service

5285 Port Royal Road

Springfield, VA 22161

phone: 800.553 .6847

fax: 703.605 .6900

email: orders@ntis.fedworld.gov

online ordering: http://www.ntis.gov/ordering.htm 


\title{
Laboratory Testing of Aerosol for Enclosure Air Sealing
}

\author{
Prepared for: \\ Building America \\ Building Technologies Program \\ Office of Energy Efficiency and Renewable Energy \\ U.S. Department of Energy \\ Prepared by: \\ Curtis Harrington and Mark Modera \\ Western Cooling Efficiency Center - UC Davis \\ Building Industry Research Alliance \\ 7407 Tam O’Shanter Dr. \\ Stockton, CA 95210
}

NREL Technical Monitor: Chuck Booten

Prepared Under Subcontract Number: KNDJ-0-40343-00

May 2012 
[This page left blank] 


\section{Contents}

Table of Figures

Table of Tables

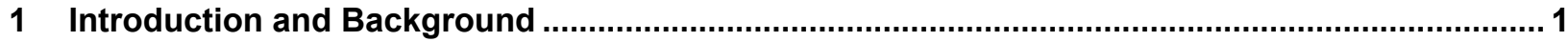

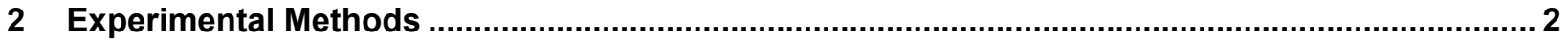

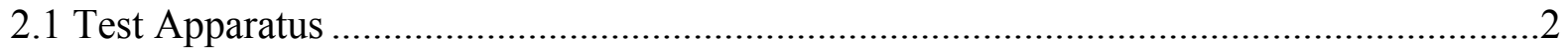

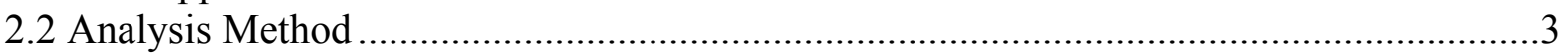

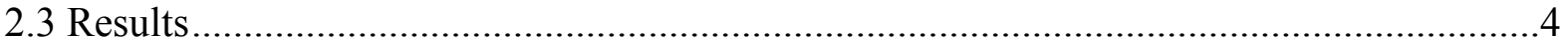

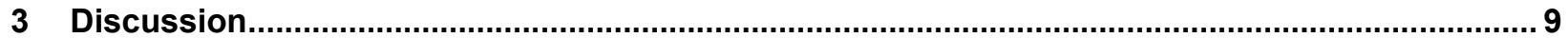

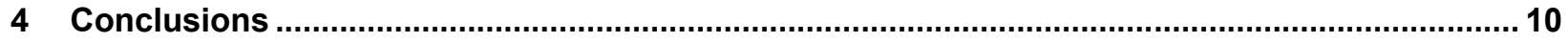

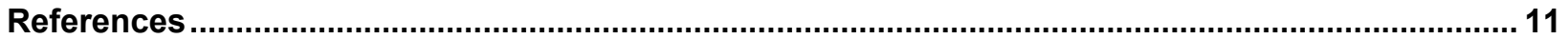

\section{Table of Figures}

Figure 1. Photos showing the enclosure and leak panels used for the small-scale tests

Figure 2. Dimensioned views of the enclosure showing the various leak locations. Each Leak panel, illustrated by the green squares, contained six slot leaks, and the sealant was introduced through the injection hole illustraed by the green circle on the front.

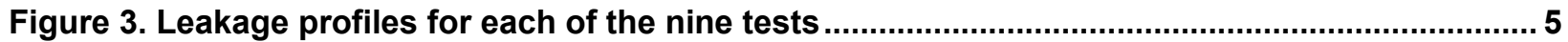

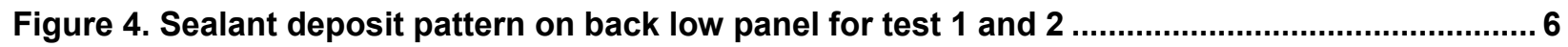

Figure 5. Typical Pressure profiles inside the enclosure during tests with no pressure control, and tests controlled at $100 \mathrm{~Pa}$ and $50 \mathrm{~Pa}$

Figure 6. Average sealant distribution for test at various pressures and $25 \mathrm{ccm}$ sealant injection rate.

Figure 7. Impact of particle size on sealant use and deposition

\section{Table of Tables}

Table 1. Test Protocol Used for Each of the Nine Tests

Unless otherwise indicated, all figures and tables were created by the Building Industry Research Alliance. 


\section{Executive Summary}

Space conditioning energy use can be significantly reduced by addressing uncontrolled infiltration and exfiltration through the envelope of a building. A process for improving the airtightness of a building envelope by sealing shell leaks with an aerosol sealing technology is presented. Retrofit and new construction applications are possible with this process during occupancy changes, the rough-in stage of new construction, or possibly from attics or crawlspaces in occupied homes. The initial research was limited to small-scale testing in a laboratory environment, and the results were very promising. All tests sealed the test enclosure from approximately $41 \mathrm{in}^{2}$ of open leakage area to nearly 0 in. of leakage area in less than 30 min. This research will help the development of an application protocol for aerosol sealing of building shells that will eventually be demonstrated on buildings in retrofit and new construction. 


\section{Introduction and Background}

Residential building shells are notoriously leaky, causing unintended flows between conditioned and unconditioned spaces that result in additional loads for the heating and air-conditioning equipment to address. One study shows that houses built in the 1990s can have as much as 180 in. ${ }^{2}$ of leakage area for a 1500- $\mathrm{ft}^{2}$ home (Sherman and Dickerhoff 1998). A significant effort has been made to reduce the leaks in building shells withh current construction practices, but the problems of high labor costs, constant vigilance, and quality control remain. The objective of this research is to develop and demonstrate a remote sealing process that uses aerosolized sealant to simultaneously measure, find, and seal leaks in a building envelope shell in an efficient and cost effective manner. The tested process involved pressurizing a space with a fog of sealant particles that travel to, and as they escape, seal the leaks.

A similar process, developed by Lawrence Berkeley National Laboratory and commercialized under the name Aeroseal, has been used to seal leaks in ducts with great success. The process injects a solution of polyvinyl acetate sealant and water into a high-pressure airstream to produce tiny droplets. A calibrated fan and heater produce the carrier flow that sends the sealant through the duct system, and evaporates the water surrounding the sealant particle. Tests at Lawrence Berkeley National Laboratory of the particle size produced by a compressed-air nozzle similar to the one used in the commercial Aeroseal machine (used for our testing) generated particles with a mean diameter around $7 \mu \mathrm{m}$. With all catastrophic leaks repaired, such as disconnected ducts, the aerosol sealants are shown to be capable of sealing approximately $80 \%$ of the leaks encountered in residential homes (Modera et al. 1996). In general, the sealing rate in duct applications was shown to vary with the width (or smallest dimension) of the leak squared (Carrie and Modera 1998). Thus although there is no well-established maximum leak size, this efficiency creates practical limitations on the size leak that can be sealed. For example, a 1/8-in. gap seals 64 times faster than a 1-in. gap, although 1-in. gaps have been sealed. For reference purposes, the company that sells the equipment for duct sealing quotes maximum practical leak sizes between $3 / 8$ in. and $5 / 8$ in. across. The work presented in this report looks at a similar process applied instead in a nominally quiescent environment without the use of a carrier flow to deliver the aerosol sealant to the location of the leaks. 


\section{Experimental Methods}

\section{$2.1 \quad$ Test Apparatus}

The Western Cooling Efficiency Center constructed an 8-ft $\times 8$ - $\mathrm{ft} \times 4$ - $\mathrm{ft}$ enclosure with leak panels distributed at various locations around the shell (Figure 1). Figure 2 presents an illustration of the location of the leak panels installed. The approximate size of each leak is 0.1 to 0.12 in. $\times 10$-in. $\times 0.125$ in. $(\mathrm{H} \times \mathrm{W} \times \mathrm{D})$; and each leak panel has six leaks. The height of each leak was meant to be representative of a typical leak in a building shell, but the depth is much shorter than what is expected to be found in buildings, so the leaks in the enclosure would tend to seal more slowly. The total measured leakage was approximately $41 \mathrm{in} .^{2}$ of open leakage area. A 14-in. diameter hole was used as the injection site to introduce the sealant fog near the top of the enclosure (see Figure 2).
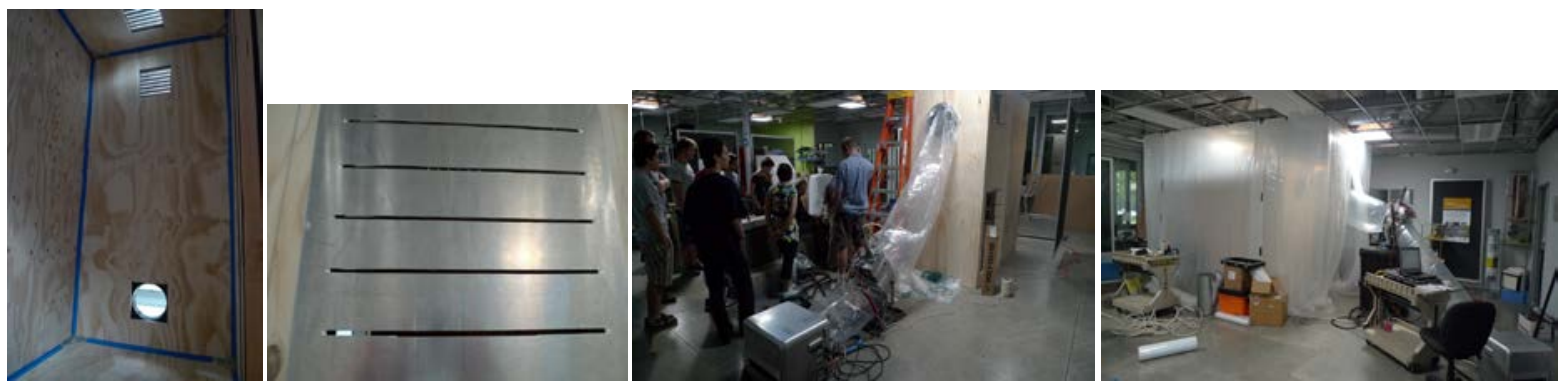

Figure 1. Photos showing the enclosure and leak panels used for the small-scale tests
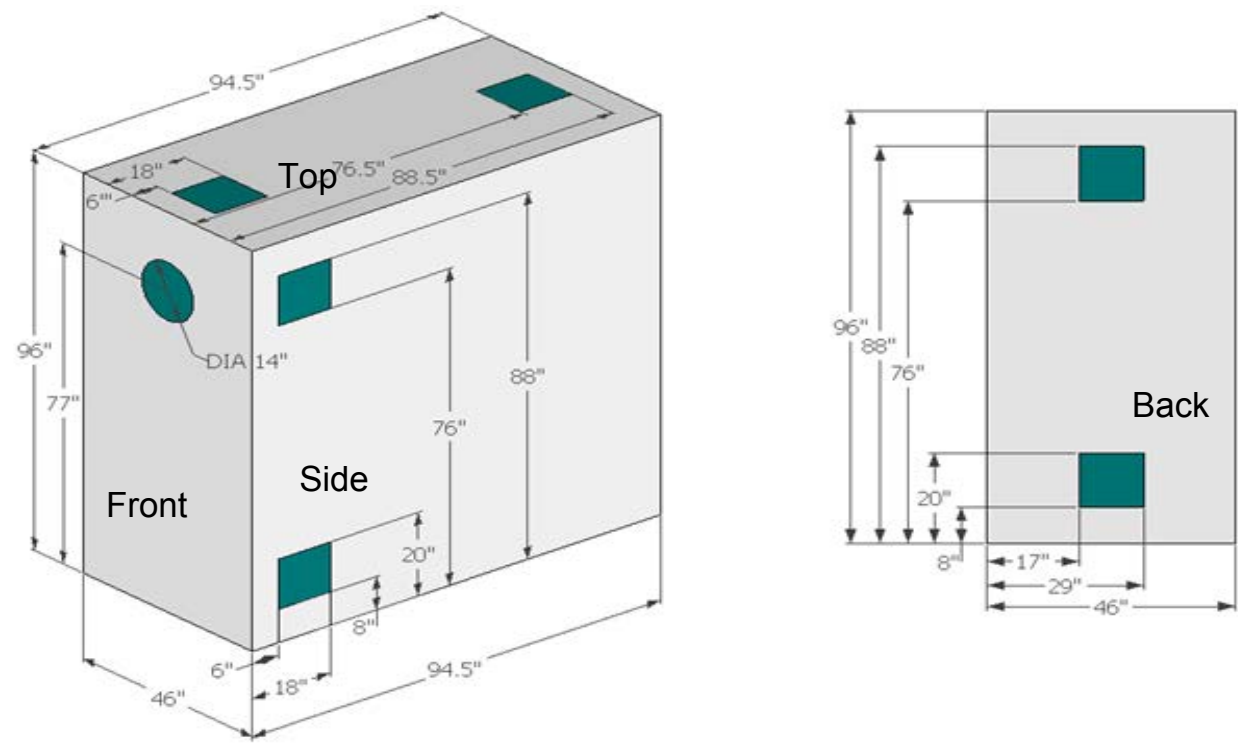

Figure 2. Dimensioned views of the enclosure showing the various leak locations. Each leak panel, illustrated by the green squares, contained six slot leaks, and the sealant was introduced through the injection hole illustrated by the green circle on the front. 


\subsection{Analysis Method}

The performance of the remote sealing technology was evaluated using three primary metrics: (1) the time needed to seal the enclosure; (2) particle deposition inside the enclosure; and (3) the uniformity of sealant deposition at the leaks. These performance metrics were used to evaluate several independent parameters to understand their effects. The parameters evaluated included the pressure inside the enclosure, the flow rate of sealant injected, and the size of the particles injected.

The commercial Aeroseal machine, although probably not appropriate for building applications, was used for our initial tests of sealing building shells. It includes instrumentation for measuring differential pressure between the enclosure and ambient, as well as for measuring the airflow, thereby facilitating continuous monitoring of leakage area during the sealing process. The leakage area was computed using Equation 1 (Carrie and Modera 2002) and Equation 2 (Batchelor 1967).

$$
\begin{gathered}
Q=E L A_{\text {ref }} \cdot \sqrt{\frac{2 \cdot \Delta P}{\rho}} \cdot\left(\frac{\Delta P}{\Delta P_{\text {ref }}}\right)^{n} \\
L A=\frac{E L A}{0.6}
\end{gathered}
$$

Where

$\begin{array}{lll}Q & = & \text { the measured airflow rate, } \\ E L A_{\text {ref }} & = & \text { the effective leakage area, } \\ \Delta P & = & \text { the pressure measured across the leak, } \\ \Delta P_{\text {ref }} & = & \text { a reference pressure (chosen to be } 25 \mathrm{~Pa}), \\ \rho & = & \text { the air density, } \\ n & = & \text { the flow exponent (typically } 0.5 \text { for an orifice), and } \\ L A & = & \text { the leakage area. }\end{array}$

The $E L A_{\text {ref }}$ of a leak is the area of a perfect nozzle that at some reference pressure will produce the same flow as the leak at that pressure. It can be shown both experimentally and through theoretical calculations that the $E L A$ is related to the actual leakage area of an orifice by a factor of 0.6 (Batchelor 1967).

A mass balance was used to determine where the sealant is ultimately deposited. Using a scale with a 0.001 gram resolution, the weight of various materials before and after sealing allowed us to track the fraction of sealant that was lost from settling or turbulent deposition onto surfaces. These materials included a sheet of plastic placed on the bottom of the test enclosure, the plastic tubing used to transport the sealant from the generation point to the enclosure, and plastic sheets placed on the walls and ceiling. In addition, the sealant deposited in each panel leak was determined by removing the sealant in and around the leak and then weighing the removed 
sealant. The results for different panels were to get a feel for the particle distribution inside the enclosure. Errors may have been introduced by not completely removing all sealant from the panels, the sample sections of plastic used for measuring wall and ceiling deposition not being representative of the entire surface, and using the manufacturer's calibration for the sealant flow rates. Assuming the pump calibration is reasonably accurate, the overall error in the measurements is expected to be within $\pm 5 \%$.

The approach for the first stage of development employed the Aeroseal equipment and applied it to sealing the test enclosure. Initially, it was expected that the particles produced by the Aeroseal equipment would be too large to allow for sufficient particle suspension. This was not the case, however, and the leaks were more than sufficiently sealed in the initial tests, though observations in the small-scale tests led to further research on the impact of reducing particle size. In addition to reducing particle size, oscillating fans could be used to assist in keeping the particles suspended and to make the indoor-air particle distribution more uniform in an actual application.

The performance of each test was evaluated using the leakage versus time profiles, as well as the analyses of sealant use efficiency quantified by the mass balance of sealant materials (fraction on floor, in leaks, on walls, and lost through leaks).

The independent variables investigated included:

- Average particle size (controlled by sealant dilution)

- Enclosure pressure control

- Sealant injection rate.

The dependent variables that were used to quantify performance included:

- Sealing rate

- Sealing uniformity (comparison of the amount of sealant deposited on panels in different locations)

- Sealant use efficiency (fraction that settles on the floor and other surfaces, versus deposited in leaks).

\subsection{Results}

Several tests of the envelope sealing process were performed, all of which showed promising results, sealing the enclosure in less than $30 \mathrm{~min}$. Each test was performed under different conditions to study the impacts of the independent variables on the sealing parameters (Table 1).

Figure 3 shows the leakage profiles for each of the nine tests in the enclosure. All tests successfully sealed the enclosure to nearly zero leakage in less than $30 \mathrm{~min}$. Note that, at the beginning of each test, the sealant lines were first purged of water before sealant reached the injection nozzle, causing a slight delay at the beginning of each test, which for $25 \mathrm{ccm}$ tests was about $5 \mathrm{~min}$ and for the $100 \mathrm{ccm}$ test was about $2 \mathrm{~min}$.

The leakage profiles show that the sealant injection rate has a significant impact on sealing time, whereas controlling the pressure inside the enclosure had a less significant impact. Tests performed at a $25 \mathrm{ccm}$ injection rate at various pressures all sealed the enclosure in 13-15 min, whereas injecting sealant at $100 \mathrm{ccm}$ sealed the enclosure in $6 \mathrm{~min}$. Reducing sealant particle size 
by diluting the sealant with water also significantly extended the sealing time. This is due to the reduced solid sealant injection rate associated with diluting without adjusting the pump rate. In the test with diluted sealant, the enclosure sealed in approximately $28 \mathrm{~min}$ (Figure 3 ).

Table 1. Test Protocol Used for Each of the Nine Tests

\begin{tabular}{c|c|c|c}
\hline $\begin{array}{c}\text { Test } \\
\text { Number }\end{array}$ & $\begin{array}{c}\text { Box Pressure } \\
\mathbf{( P a )}\end{array}$ & $\begin{array}{c}\text { Sealant Injection Rate } \\
(\mathbf{c c m})\end{array}$ & Sealant Dilution \\
\hline $\mathbf{1}$ & No pressure/flow control & 100 & No Dilution \\
$\mathbf{2}$ & 100 & 25 & No Dilution \\
$\mathbf{3}$ & No pressure/flow control & 25 & No Dilution \\
$\mathbf{4}$ & 50 & 25 & No Dilution \\
$\mathbf{5}$ & 100 & 25 & No Dilution \\
\hline $\mathbf{6}$ & 50 & 25 & No Dilution \\
$\mathbf{7}$ & 100 & 25 & No Dilution \\
\hline $\mathbf{8}$ & 50 & 25 & No Dilution \\
$\mathbf{9}$ & 100 & 25 & 1 part sealant/1 part water \\
\hline
\end{tabular}

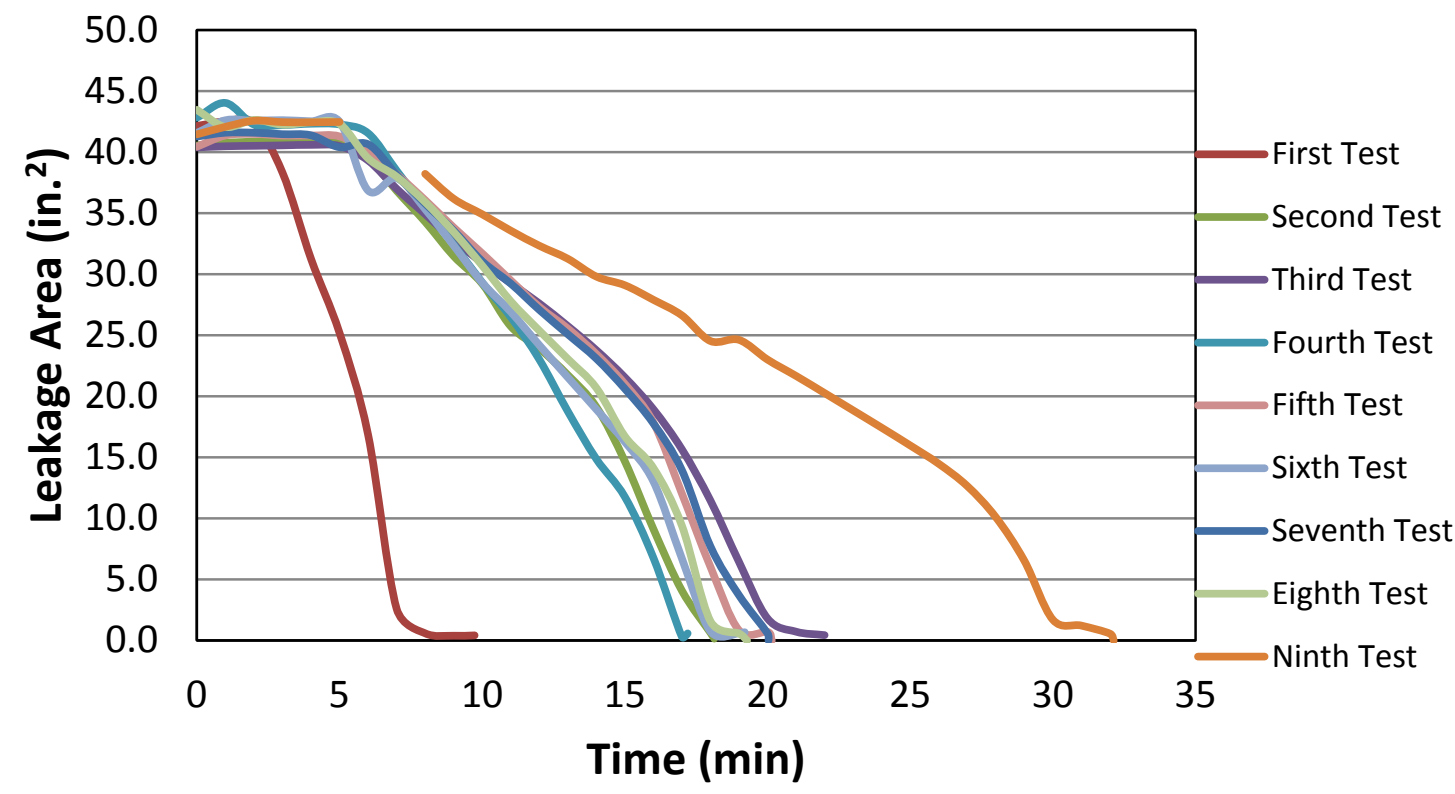

Figure 3. Leakage profiles for each of the nine tests

The sealant deposition pattern could be a quick indication of the sealant use efficiency. Figure 4 shows the sealant deposition pattern observed during a high sealant flow application and another at low sealant flow application. The large spread of sealant across the leak in the $100 \mathrm{ccm}$ test indicates that more sealant was deposited in and around the leak. The deposition patterns for all 
tests performed at a $25 \mathrm{ccm}$ injection rate were similar, showing a much cleaner seal. We believe that this implies better sealant use efficiency at lower sealant injection flows. Comparing the sealant deposition in and around the leaks for different panels (leak locations) showed very little variance. There was only a $1 \%-2 \%$ variation in the mass of sealant deposited in any of the leak panels distributed around the enclosure, suggesting very good particle distribution and sealing uniformity for all tests performed.

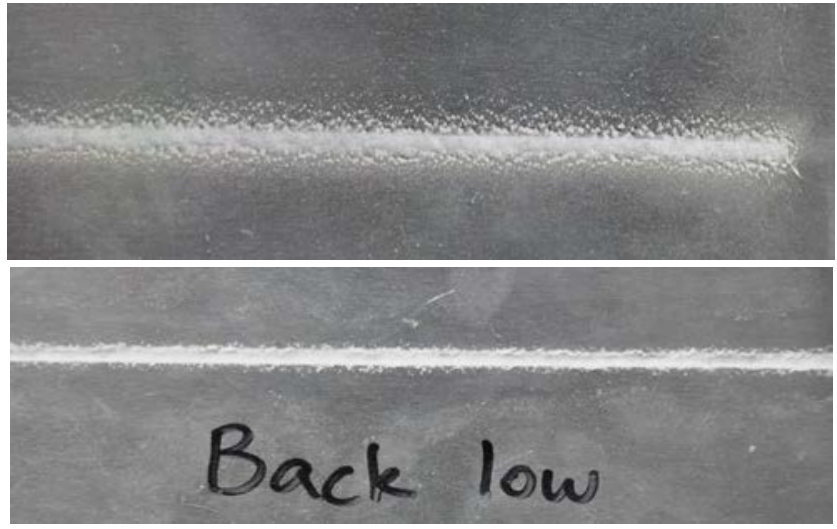

Typical pattern for $100 \mathrm{ccm}$ injection rate

Typical pattern for $25 \mathrm{ccm}$ injection rate

Figure 4. Sealant deposit pattern on back low panel for tests 1 and 2

The pressure was regulated by a calibrated fan that controlled the airflow delivered to the test enclosure. Three operating pressures were studied in the small-scale tests: (1) no pressure control (which effectively allows the fan curve of the Aeroseal machine to control the injection flow); (2) manual flow control to maintain 100 Pa pressure differential: and (3) manual flow control to maintain $50 \mathrm{~Pa}$ pressure differential. Because a very low leakage level was achieved by injecting aerosol sealant, the pressure inside the enclosure became difficult to control as the flow approached the minimum achievable by the equipment (Figure 5). Better control of the pressure inside building shells for the duration of the installation of aerosol sealant will be needed to avoid overpressurizing the space.

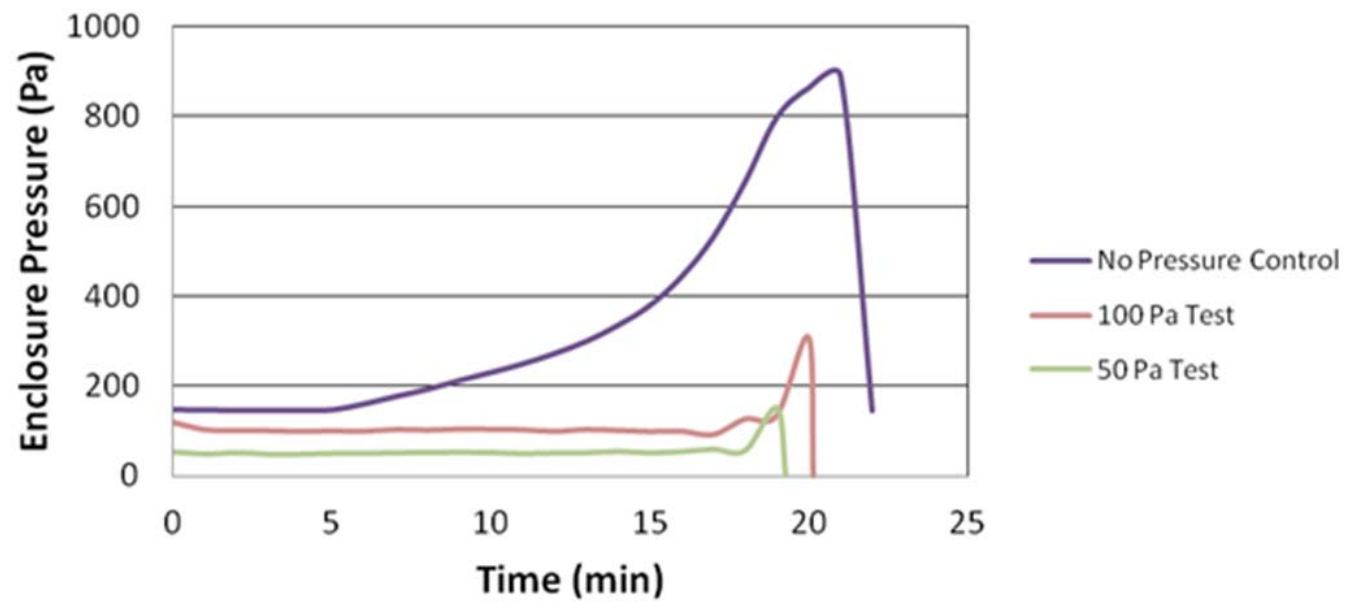

Figure 5. Typical pressure profiles inside the enclosure during tests with no pressure control, and tests controlled at $100 \mathrm{~Pa}$ and $50 \mathrm{~Pa}$ 
The mass balance analysis allows for accurate tracking of where the sealant is ultimately deposited. The sealant distributions in Figure 6 show how pressure control affects the sealing process. There is a clear trend showing that lower enclosure pressure leads to less sealant deposited in and around the leaks, more sealant depositing on the floor, less sealant depositing on the walls and ceiling, and more sealant being blown through the leaks. Although most sealant injected was blown through the leaks, it is expected that the geometry of leaks in typical buildings will be different than the test enclosure. The longer flow path of typical leaks in buildings is expected to reduce the amount of sealant blown through and, therefore, improve the efficiency of sealant use. The typical building leak sealed during this process would be at the joints and seams between building materials that are much deeper then the leaks tested in the laboratory enclosure. Deeper leaks reduce the angle of trajectory that would allow a particle to pass through the leak without impacting a wall and depositing. Laboratory tests of aerosol duct sealing showed similar results, measuring about $25 \%$ of sealant depositing in a slot leak at 100 $\mathrm{Pa}$ (Carrie and Modera 2002), whereas our tests show about 21\% of sealant depositing in the leak under the same conditions. The machine generating the aerosol in Carrie and Modera (2002) was a different injector that produced larger particle sizes. Smaller particles lead to more sealant blown through the leak, which may account for the less efficient sealant deposition in our tests.
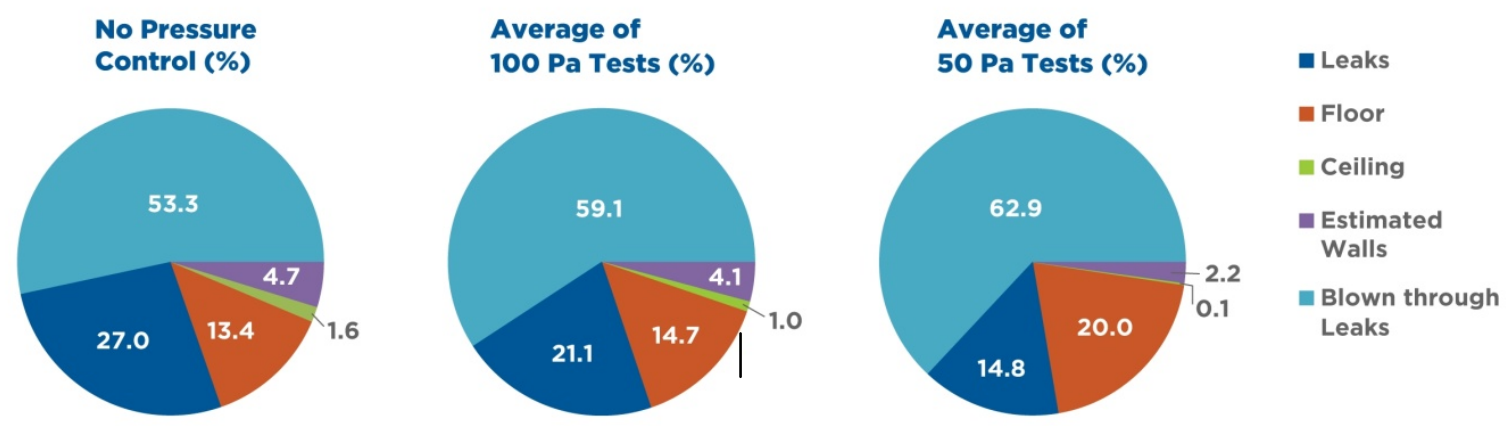

Figure 6. Average sealant distribution for test at various pressures and $25 \mathrm{ccm}$ sealant injection rate

Manipulating sealant particle size was intended to reduce particle settling in the enclosure. To generate smaller particles, the sealant mixture was diluted with a one-to-one mixture of sealant and water, thereby reducing the particle diameter by about $20 \%$ on average. Figure 7 compares the sealant use and distribution during the test of diluted sealant and other tests at similar pressures. The diluted test used slightly more sealant than the other tests with a significant increase in the amount that was blown through leaks. Surprisingly, there was no impact on the amount of sealant that settled on the ground compared to the 100 Pascal tests. Because smaller particles have longer settling times, it was expected that less sealant would settle on the floor and the sealant particles would distribute better throughout the test enclosure. This was not observed in the small-scale tests. This could be the result of the enclosure size, but more likely is due to the longer injection period. Another test that uses the same rate of solid sealant injection with the smaller sealant particles should be conducted. 


\section{u.s. DEPARTMENT OF | Energy Efficiency \& \\ ENERCY Renewable Energy}

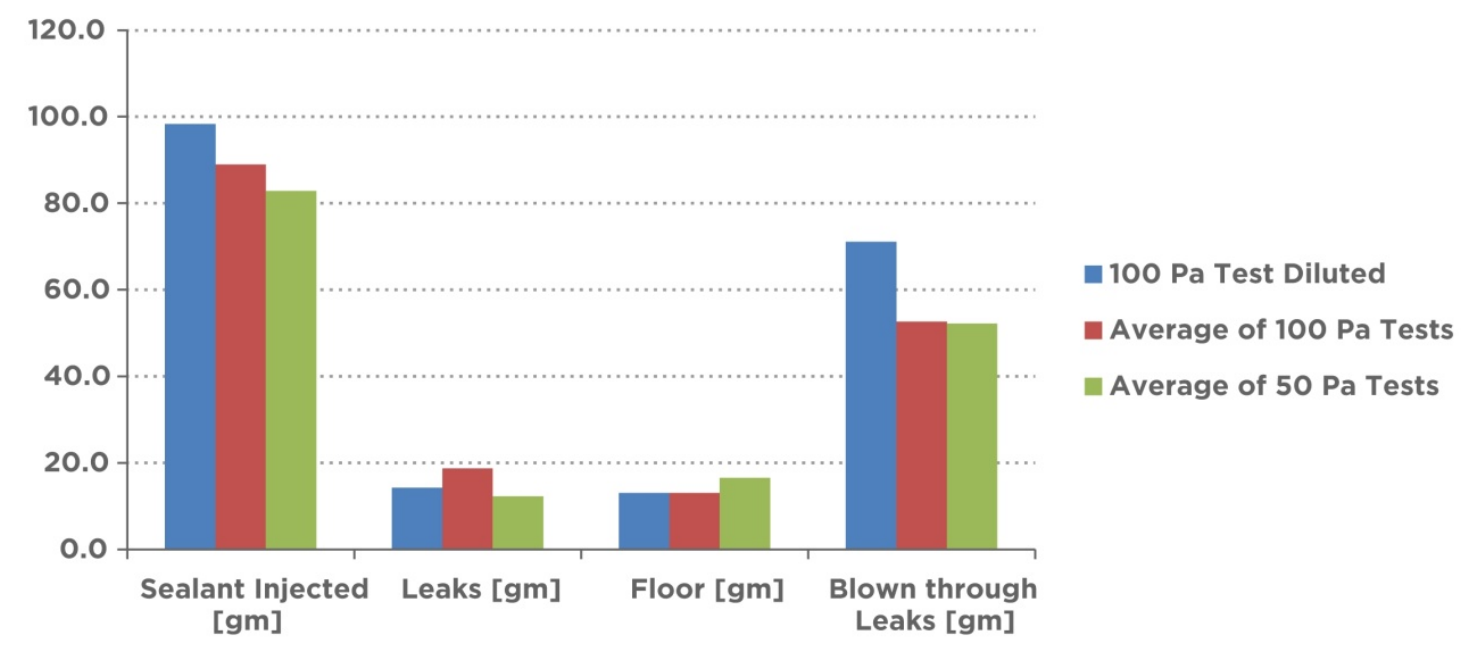

Figure 7. Impact of particle size on sealant use and deposition 


\section{Discussion}

The small-scale tests of a remote sealing process using aerosol sealant were very successful, and were as good as, or better than, that experienced in ducts. The sensitivity tests show that reducing the pressure in the enclosure increased the sealant required to seal the same leaks, principally by reducing excess deposition around the leaks, more than making up for a bit more sealant deposition on the floor. Lower pressures also reduced the amount of sealant that deposits on the ceiling and walls. Most small-scale tests were performed at $50 \mathrm{~Pa}$ and $100 \mathrm{~Pa}$, as these are the expected operating pressures for a test in an actual building. The tests results at these pressures were very similar, making it difficult to conclude which will be better in actual buildings.

One problem with the small-scale testing performed was that the size of the space does not allow us to see all the effects of changing a given parameter. For example, smaller particles could be more beneficial in a space with larger horizontal dimensions (more floor area, but the same ceiling height). For similar reasons, oscillating fans for reducing particle settling times were not tested, although they could be useful for applications in larger spaces. Particle size reduction and oscillating fans will be explored further in tests of the sealing process in actual buildings.

This technology is expected to cost much less than manually sealing a home and to be much more effective, though more research is needed for better cost estimates. Assuming the sealing rate is similar in an actual application, the results of the small-scale tests show that a typical $1500-\mathrm{ft}^{2}$ house would require less than $1 / 2$ gal of sealant solution to seal the leaks. The preparation of a house for sealing includes setting up a blower door, covering the floor with plastic, taping off leaks that we do not want to seal (e.g., gaps between double-hung windows), and taping off exhaust ducts and flues. The sealing process would take a technician about four hours to prepare and complete. The sealant used for duct sealing is sold for about $\$ 50 /$ gal, so with a billing rate of $\$ 50 / \mathrm{h}$ for the technician, a reasonable cost estimate for sealing a $1500-\mathrm{ft}^{2}$ home might be $\$ 250$. 


\section{Conclusions}

Sealing buildings shells can have a large impact on building energy use, as it reduces uncontrolled airflows between conditioned and unconditioned spaces. A method for quickly sealing building shells using an aerosol sealant has been demonstrated in a small, nominally quiescent test enclosure with very promising results. Several tests were performed to test the sensitivity of several independent variables on the sealing process, including internal enclosure pressure and particle size. In all tests the enclosure was sealed from $41 \mathrm{in}^{2}$ of total leakage area to less than $1 \mathrm{in}^{2}$ of total leakage area in less than $30 \mathrm{~min}$. This laboratory testing of the technology will be used to develop an application protocol for aerosol sealing of building shells. Further research is planned to demonstrate the shell sealing protocol in retrofit and newconstruction applications. 


\section{References}

Batchelor, G.K. (1967). An Introduction to Fluid Dynamics. Cambridge University.

Carrie, F.R.; Modera, M.P. (1998). "Particle Deposition in a Two-Dimensional Slot from a Transverse Stream.” Aerosol Science and Technology vol. 28, pp. 235-246.

Carrie, F.R.; Modera, M.P. (2002). "Experimental Investigation of Aerosol Deposition on Slotand Joint-Type Leaks.” Aerosol Science vol. 33, pp. 1447-1462.

Modera, M.P.; Dickerhoff, D.; Nilssen, O.; Orlando, E. Duquette, H.; Geyselaers, J. (1996).

"Residential Field Testing of an Aerosol-Based Technology for Sealing Ductwork." Proceedings of ACEEE Summer Study, Pacific Grove, CA, 1996.

Sherman, M.; Dickerhoff, D. (1998). Air-Tightness of US Dwellings, L.B.N.L. Energy Performance of Building Group, Editor. 


\section{U.s. DEPARTMENT OF Energy Efficiency \& ENERCY Renewable Energy}

